\title{
Oral Health Care Behavior Differences Between Dental and Biomedical Engineering Students Comparing Oral Care of Dental and Engineering Students
}

\author{
Ayşe KOÇAK-BÜYÜKDERE ${ }^{(1)}$ \\ Department of Prosthodontics, \\ Kocaeli University, \\ Faculty of Dentistry, \\ Kocaeli, Turkey \\ Sarkis SÖZKES ${ }^{(2)}$ \\ (Corresponding Author) \\ Department of Biomaterials, \\ Biomedical Engineering,
}

\author{
Tekirdag Namık Kemal University, \\ Faculty of Engineering, \\ Tekirdağ, Turkey \\ Melisa BOZKURT ${ }^{(3)}$ \\ Department of Oral and Maxillofacial Radiology, \\ Marmara University, \\ Faculty of Dentistry, \\ İstanbul, Turkey
}

\section{Abstract}

\section{Objectives:}

The aim of the study was to compare the oral hygiene habits of students from different provinces and universities, from the dental faculty and biomedical engineering. Another aim was to analyze development of dental care habits during growth in relation to education both the parent and the student himself.

\section{> Methods:}

University students were asked to answer the survey on voluntary basis. 244 students have answered the questions; gender, year of birth, study level, education of their parents, their toothbrushing habit and oral health level awareness were questioned in detail.

\section{$>$ Results:}

Of the 244 volunteers, 122 study at the faculty of dentistry, whereas the other 122 study at the biomedical engineering faculty. While $53.7 \%$ of all participants brush their teeth after breakfast and $94.3 \%$ brush before bedtime, $81.1 \%$ of dentistry students brush twice a day, whereas the ratio of biomedical students brushing twice a day is $\mathbf{5 9 . 8 \%}$.

On the one hand, $99.2 \%$ of dentistry students brush their teeth before going to bed whereas, biomedical students were $89.3 \%$, which indicates a significant difference. Dental floss utilization among dental students was higher than the biomedical students, and the difference was statistically significant. For self-assessment of their oral hygiene habits, both groups have evaluated themselves between ordinary and well.

\section{Conclusion:}

Tooth brushing habit is initially adopted from the family. Correct brushing is established upon the guidance of the dentist. Therefore, teaching proper toothbrushing techniques to the families should be aimed. This will enable socially healthier oral hygiene, thus creating high awareness communities.

Keywords:- Oral hygiene, Oral health, Toothbrushing.

\section{INTRODUCTION}

Oral hygiene should start as soon as the teeth have erupted. Awareness of the people taking care of babies affects the habit of brushing teeth. The duration of this routine is essential in terms of the time and the manner of brushing teeth. Education and awareness of the caretakers of the children on this topic will ensure better and long-term oral and gingival health[1-5]. As the brushing teeth set the grounds of oral hygiene, cleaning between the teeth is accepted as a golden rule[1, 6].

Some studies indicate the significance of the toothpaste and its ingredients in oral health[7]. Furthermore, feeding habits have significant importance in terms of periodontal health as they affect systematical health. Cleaning teeth after consuming sticky foods decreases the incidence of caries[8].

Although all surfaces of teeth require the same amount of attention during tooth brushing, studies show that individuals brush the front sides of their teeth in a better manner compared to the backsides[9].

Brushing teeth, flossing, using mouthwash, and cleaning the tongue twice a day, along with eating healthily and regularly visiting dentists, reduce the risk of gingival diseases as well as caries[10-12]. This will ensure that individuals have healthy oral structures while supporting conservative dental treatments. 
In this study, a comparison was made between the two faculties utilizing the survey method. The assumption is that, due to education received in the faculty of dentistry and interests of the students therein, results from the faculty of dentistry will be better than the biomedical department.

The purpose of this study is to compare the oral hygiene habits of students from different provinces and universities. Our null hypothesis is that the results from the departments of dentistry and biomedical engineering will be the same in terms of primary dental care. Whereas another hypothesis of ours is that dental care habits developed during growth periods of the persons might be more influential, yet with the education in time, it might vary in detail.

\section{STUDY POPULATION AND METHODOLOGY}

This study received ethical approval from the NonInvasive Clinical Research Ethics Committee, School of Dentistry, Kocaeli University Turkey (KÜ GOKAEK 2018/232).

Students were asked to answer the survey on voluntary basis as taking the survey and leave the survey in the boxes outside the class. 244 students were answered the surveys. Except for gender, year of birth, and university study level, no other personal information was requested.

We have started the survey questions by querying the education of their parents, in order to establish whether the education of the family has an impact on the family individuals' oral health. After that, personal characteristics were assessed where we asked their reasons for toothbrushing and from whom or where they have learned how to brush. In order to understand the toothbrushing habits of participants, we tried to determine how many times and for how many minutes they brushed during the day. Due to the adverse effects of sugary foods on oral health, we asked whether they brush their teeth after eating sugary foods and how often they do, if they are brushing.

In order to find out whether the choice of toothbrushing tools are made consciously, we asked details regarding toothbrush bristles and how often they changed their brushes. We made an effort to determine the toothpaste using habits among persons. We questioned how much toothpaste they apply on the brush and whether they take the reasons described by the manufacturers into consideration for their selection. In order to ascertain the level of awareness on that 'cleaning between teeth' is accepted as a golden rule along with toothbrushing, they have been asked questions on cleaning between teeth and how many sides of teeth they have been cleaning.

Other than brushing and backside cleaning, we have asked whether they have a habit of cleaning their tongues, and if they perceived all cleaning activities they have been carrying out, and forceful brushing is the correct approach. After answering all questions, we have requested them to comment on their oral hygiene. The survey results have been assessed via SPSS 22.0 Windows version. The relation between categorical variables was tested by Chi-square test. Introductory statistics for categorical variables are provided as numbers and percentages. $\mathrm{p}<0.05$ is considered significant.

\section{> Methodological Limitations:}

In this study, participants were selected from two different universities. If the number of universities is increased for a more accurate ratio between genders, the evaluations will reflect larger groups.

The purpose of the survey questions is to increase the awareness of the people. It is believed that by explaining the ideal brushing after questions, conducting a follow-up survey upon a specified period, with the same questions, will ensure the further success of this type of study.

\section{RESULTS}

The study is conducted with 244 students, 122 of which are studying the Dentistry Department, and the other 122 are studying Engineering. $67.6 \%$ of the students were female, and $32.4 \%$ were male. $60.8 \%$ of them were 22 years old or younger, and $39.2 \%$ were 23 years or older. $1.6 \%$ were students of 1 st year, $33.6 \%$ were of 2 nd year, $11.1 \%$ were of $3 \mathrm{rd}$ year, $38.1 \%$ were of 4 th year, and $15.6 \%$ were of 5 th year.

\begin{tabular}{|c|c|c|c|}
\hline \multicolumn{2}{|c|}{} & Dentistry & Pngineering \\
\cline { 2 - 4 } & & $\mathbf{n}(\%)$ & $\mathbf{n}(\%)$ \\
\hline \multirow{3}{*}{ Class } & $1^{\text {st }}$ class & $0(0 \%)$ & $4(3,3 \%)$ \\
\cline { 2 - 4 } & $2^{\text {nd }}$ class & $24(19.7 \%)$ & $58(47.5 \%)$ \\
\cline { 2 - 4 } & $3^{\text {rd }}$ class & $23(18.9 \%)$ & $4(3.3 \%)$ \\
\cline { 2 - 4 } & $4^{\text {th }}$ class & $39(32 \%)$ & $54(44.3 \%)$ \\
\hline \multirow{3}{*}{ Gender } & $5^{\text {th }}$ class & $36(9.5 \%)$ & $2(1.6 \%)$ \\
\cline { 2 - 4 } & Female & $91(74.6 \%)$ & $74(60.7 \%)$ \\
\hline \multirow{2}{*}{ Age } & Male & $31(25.4 \%)$ & $48(39.3 \%)$ \\
\hline
\end{tabular}


ISSN No:-2456-2165

\begin{tabular}{|c|c|c|c|}
\hline \multirow{4}{*}{ Mother Education } & Primary school & $29(23.85)$ & $60(49.2 \%)$ \\
\cline { 2 - 4 } & Secondary school & $19(15.6 \%)$ & $27(22.1 \%)$ \\
\cline { 2 - 4 } & Highschool & $41(33.6 \%)$ & $20(16.4 \%)$ \\
\cline { 2 - 4 } & University and higher & $33(27 \%)$ & $15(12.3 \%)$ \\
\hline \multirow{3}{*}{ Father Education } & Primary school & $18(14.8 \%)$ & $37(30.3 \%)$ \\
\cline { 2 - 4 } & Secondary school & $14(11.5 \%)$ & $28(23 \%)$ \\
\cline { 2 - 4 } & Highschool & $42(34.4 \%)$ & $31(25.4 \%)$ \\
\cline { 2 - 4 } & University and higher & $48(39.3 \%)$ & $26(21.3 \%)$ \\
\hline
\end{tabular}

Table 1:- Evaluation of the general students

There is no significant difference between the faculties in terms of the distribution of the students among classes (p:0.000; $\mathrm{p}<0.05$ ). While the ratio of 3rd and 5th-grade dentistry faculty students is higher than that of the faculty of engineering, the rate of 2 nd and 4 th-grade engineering faculty students is higher than of the dentistry faculty (Table
1). The ratio of female students in the faculty of dentistry $(74.6 \%)$ is statistically significantly higher than the faculty of Engineering (60.7\%) (p: $0.020 ; \mathrm{p}<0.05)$. The ratio of students at the faculty of dentistry at the age of 23 and over $(47.5 \%)$ is statistically significantly higher than the engineering faculty $(30.5 \%)$ ( $\mathrm{p}: 0.007 ; \mathrm{p}<0.05)$.

\begin{tabular}{|c|c|c|c|c|}
\hline & & Dentistry & Engineering & $\mathbf{p}$ \\
\hline & & $\mathrm{n}(\%)$ & $\mathrm{n}(\%)$ & 1 \\
\hline \multirow{5}{*}{ Purpose for brushing } & Avoiding germs & $55(45.5 \%)$ & $50(41 \%)$ & \multirow[t]{5}{*}{$0,001 *$} \\
\hline & Whitening teeth & $5(4.1 \%)$ & $21(17.2 \%)$ & \\
\hline & Preventing tartar formation & $16(13.2 \%)$ & $13(10.7 \%)$ & \\
\hline & Removing bad breath & $3(25 \%)$ & $11(9 \%)$ & \\
\hline & More than one reason & $42(34.7 \%)$ & $27(22.1 \%)$ & \\
\hline \multirow{4}{*}{ Brushing frequency } & None & $0(0 \%)$ & $3(2.5 \%)$ & \multirow[t]{4}{*}{$0,000 *$} \\
\hline & 1 time per day & $10(8.2 \%)$ & $34(27.9 \%)$ & \\
\hline & 2 times per day & $99(81.1 \%)$ & $73(59.8 \%)$ & \\
\hline & 3 times per day or more & $13(10.7 \%)$ & $12(9.8 \%)$ & \\
\hline \multirow{4}{*}{ Duration of brushing } & $0-1$ minute & $9(7.6 \%)$ & $13(10.7 \%)$ & \multirow[t]{4}{*}{0,558} \\
\hline & $1-2$ minutes & $56(47.1 \%)$ & $58(47.5 \%)$ & \\
\hline & 2-3 minutes & $46(38.7 \%)$ & $47(38.5 \%)$ & \\
\hline & Longer than 3 minutes & $8(6.7 \%)$ & $4(3.3 \%)$ & \\
\hline \multirow{6}{*}{$\begin{array}{c}\text { From whom have you } \\
\text { learned }\end{array}$} & Family & $59(48.4 \%)$ & $78(64.5 \%)$ & \multirow[t]{6}{*}{$0,003 *$} \\
\hline & Dentist & $19(15.6 \%)$ & $7(5.8 \%)$ & \\
\hline & Brochure & $4(3.3 \%)$ & $1(0.8 \%)$ & \\
\hline & TV & $2(1.6 \%)$ & $6(5 \%)$ & \\
\hline & Self-taught & $32(26.2 \%)$ & $29(24 \%)$ & \\
\hline & More than one source & $6(4.9 \%)$ & $0(0 \%)$ & \\
\hline${ }^{+}$Brushing at night & Never & $1(0.8 \%)$ & $13(10.7 \%)$ & $0,002 *$ \\
\hline
\end{tabular}

Chi-square test ${ }^{+}$Continuity (yates) correction $\quad{ }^{*} p<0.05$

Table 2:- Evaluation of the general characteristics of brushing by faculty

There is a statistically significant difference between the education level of the mothers based on the faculties (p: $0.000 ; \mathrm{p}<0.05)$. The ratio of the mothers of dentistry faculty students whose education level is high school or higher is significantly higher than those of the faculty of Engineering.

There is a statistically significant difference between the education levels of the fathers based on the faculties ( $\mathrm{p}$ : $0.000 ; p<0.05)$. The ratio of the fathers of dentistry faculty students whose education level is high school or higher is significantly higher than those of the faculty of Engineering.
There is a statistically significant difference between the faculties (Table 2) in terms of students' tooth brushing purposes ( $\mathrm{p}: 0.001 ; \mathrm{p}<0.05)$. Toothbrushing rates of the dentistry students due to the combination of several causes $(34.7 \%)$ are significantly higher than Engineering students $(22.1 \%)$ The ratio of dentistry students brushing two times a day $(81.1 \%)$, is statistically significantly higher than Engineering students $(59.8 \%)$ (p: $0.000 ; \mathrm{p}<0.05)$. 
There is no statistically significant difference between the faculties in terms of tooth brushing duration $(p>0.05)$. There is a statistically significant difference between the faculties based on whom the students learned to brush their teeth (p: $0.003 ; \mathrm{p}<0.05$ ). While the rate of engineering students who learned to brush their teeth from parents $(64.5 \%)$ was higher than that of dentistry students $(48.4 \%)$; the ratio of Dentistry students who learned it from a dentist $(15.6 \%)$ is significantly higher than engineering students $(5.8 \%)$.

There is no statistically significant difference between faculties in terms of brushing in the morning ( $p>0.05)$. The rate of engineering students not brushing their teeth at night $(10.7 \%)$ is statistically significantly higher than dentistry students $(0.8 \%)$ (p: $0.002 ; \mathrm{p}<0.05)$. There is no statistically significant difference between the faculties in terms of the frequency of tooth brushing after sugary food ( $p>0.05)$.

There is a statistically significant difference between the faculties (Table 3) in terms of toothpaste properties (p: $0.005 ; \mathrm{p}<0.05$ ). While among dentistry students, the rate of choosing a paste due to the protective feature and more than one feature is high; the highest rating cause for selecting a toothpaste among engineering students is whitening properties. There is a statistically significant difference between the faculties based on the amount of toothpaste used by the students ( $\mathrm{p}: 0.001 ; \mathrm{p}<0.05$ ). While the rate of engineering students applying toothpaste on half of the brush $(47.1 \%)$ is higher than that of dentistry students $(32 \%)$;
Dentistry students' toothpaste application rate of less than half of the brush $(59.8 \%)$ is significantly higher than engineering students $(34.7 \%)$. There is a statistically significant difference between the faculties based on the interface cleaning tools used by the students (p: $0.001 ; \mathrm{p}$ $<0.05)$.

While the rate of toothpick use of engineering students $(19.7 \%)$ is higher than that of dentistry students $(2.5 \%)$; Dentistry students' use of dental floss $(63.9 \%)$ is significantly higher than engineering students (34.4\%). Dentistry students' use of dental floss (63.3\%) is significantly higher than engineering students $(33.6 \%)$ (p: $0.000 ; \mathrm{p}<0.05)$.

There is a statistically significant difference between the faculties in terms of dental care products used by students ( $\mathrm{p}$ : $0.004 ; \mathrm{p}<0.05$ ). While the gum-chewing rates of engineering students (19\%) are higher than those of Dentistry students (5.9\%); Dentistry students' use of electric toothbrushes $(11.9 \%)$ is significantly higher than engineering students $(2.5 \%)$. There is no statistically significant difference between the faculties in terms of the rate of tongue brush use ( $\mathrm{p}>0.05)$.

There is a statistically significant difference between the faculties in terms of the answers given to the question, "Is forceful brushing effective?" (P: 0.000; p <0.05). The rate of dentistry students strictly disagreeing with such suggestion $(40.5 \%)$ is significantly higher than Engineering students $(19.7 \%)$. There is no statistically significant difference between the faculties in terms of surface cleaning of teeth $(\mathrm{p}>0.05)$.

\begin{tabular}{|c|c|c|c|c|}
\hline & & Dentistry & Engineering & $\overline{\mathbf{P}}$ \\
\hline & & n $(\%)$ & n $(\%)$ & \\
\hline \multirow{6}{*}{ Paste features } & Germicidal & $12(9.8 \%)$ & $12(9.8 \%)$ & \multirow[t]{6}{*}{$0,005^{*}$} \\
\hline & Anti-tartar & $7(5.7 \%)$ & $8(6.6 \%)$ & \\
\hline & Protective & $52(42.6 \%)$ & $38(31.1 \%)$ & \\
\hline & Whitening & $21(17.2 \%)$ & $45(36.9 \%)$ & \\
\hline & No idea & $2(1.6 \%)$ & $5(4.1 \%)$ & \\
\hline & More than one feature & $28(23 \%)$ & $14(11.5 \%)$ & \\
\hline \multirow{4}{*}{ Paste amount } & The whole brush & $6(4.9 \%)$ & $13(10.7 \%)$ & \multirow[t]{4}{*}{$0,001 *$} \\
\hline & Half of the brush & $39(32 \%)$ & $57(47.1 \%)$ & \\
\hline & Less than half of the brush & $73(59.8 \%)$ & $42(34.7 \%)$ & \\
\hline & Does not pay attention & $4(3.3 \%)$ & $9(7.4 \%)$ & \\
\hline \multirow{5}{*}{ Interface cleaning } & Does not clean & $28(23 \%)$ & $42(34.4 \%)$ & \multirow[t]{5}{*}{$0,000 *$} \\
\hline & Dental floss & $78(63.9 \%)$ & $42(34.4 \%)$ & \\
\hline & Interface tooth brush & $11(9 \%)$ & $14(11.5 \%)$ & \\
\hline & Toothpick & $3(2.5 \%)$ & $24(19.7 \%)$ & \\
\hline & More than one tool & $2(1.6 \%)$ & $0(0 \%)$ & \\
\hline \multirow{2}{*}{ Dental floss use } & Does not use & $44(36.7 \%)$ & $79(66.4 \%)$ & \multirow[t]{2}{*}{$0,000 *$} \\
\hline & Do use & $76(63.3 \%)$ & $40(33.6 \%)$ & \\
\hline
\end{tabular}


ISSN No:-2456-2165

\begin{tabular}{|c|c|c|c|}
\hline \multirow{5}{*}{ Dental care products } & Only toothbrush & $40(33.9 \%)$ & $35(28.9 \%)$ \\
\cline { 2 - 4 } & Mouthwash & $31(26.3 \%)$ & $29(24 \%)$ \\
\cline { 2 - 4 } & Water flosser & $1(0.8 \%)$ & $3(2.5 \%)$ \\
\cline { 2 - 4 } & Electric toothbrush & $14(11.9 \%)$ & $3(2.5 \%)$ \\
\cline { 2 - 4 } & Gore than one product & $7(5.9 \%)$ & $23(19 \%)$ \\
\hline \multirow{3}{*}{\begin{tabular}{c} 
Tongue brush \\
\cline { 2 - 4 }
\end{tabular}} & Does not use & $25(21.2 \%)$ & $28(23.1 \%)$ \\
\hline \multirow{3}{*}{$\begin{array}{c}\text { Teeth surface } \\
\text { cleaning }\end{array}$} & Do use & $36(71.1 \%)$ & $93(76.9 \%)$ \\
\cline { 2 - 4 } & Visible surfaces of all teeth & $11(9 \%)$ & $28(23.1 \%)$ \\
\cline { 2 - 4 } & All surfaces of all teeth & $60(49.2 \%)$ & $10(8.3 \%)$ \\
\cline { 2 - 4 } & All surfaces the brush can reach & $47(38.5 \%)$ & $7(5.8 \%)$ \\
\hline
\end{tabular}

Chi-square test $* p<0.05$

Table 3:- Evaluation of information on dental care products by faculty

There is no statistically significant difference (Table 4) between tooth brushing frequencies according to the mothers' education ( $p>0.05$ ). 70.8\% of those whose mothers are primary school graduates, $73.9 \%$ of those whose mothers are secondary school graduates, $68.9 \%$ of those whose mothers are high school graduates, $68.8 \%$ of those whose mothers are university and above are brushing their teeth once a day. There is no statistically significant difference between tooth brushing frequencies according to the fathers' education ( $p>0.05$ ). $70.9 \%$ of those whose fathers are primary school graduates, $78.6 \%$ of those whose fathers are secondary school graduates, $72.6 \%$ of those whose fathers are high school graduates, $63.5 \%$ of those whose fathers are university and above are brushing their teeth once a day.

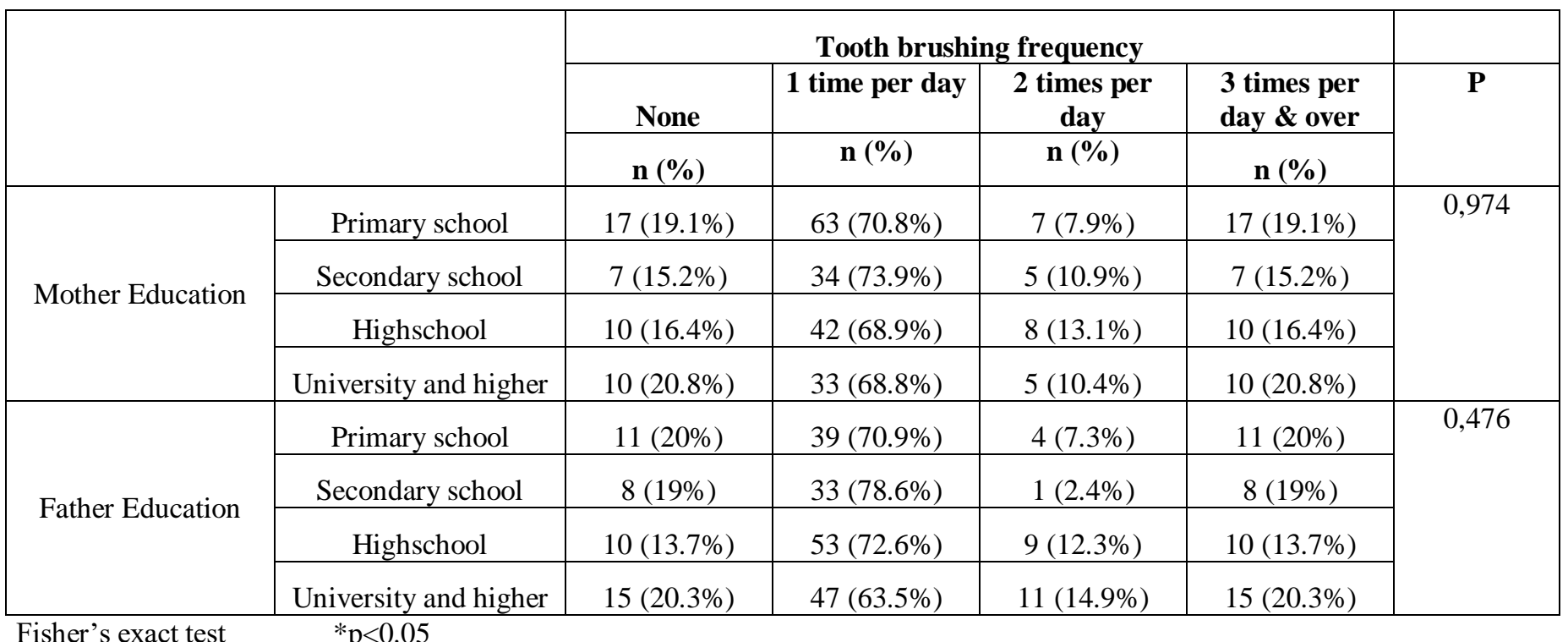

Table 4:- Evaluation of tooth brushing frequency according to parent education

There is no statistically significant difference between the frequency of tooth brushing based on the educational level of the mothers and fathers of the dental faculty students ( $p>0.05)$. There is no statistically significant difference between the frequency of tooth brushing based on the educational level of the mothers of engineering students (p> 0.05). There is a statistically significant difference between the frequency of tooth brushing based on the educational level of the fathers of the engineering faculty students (p: 0.017; p <0.05).
While the ratio of students brushing their teeth one time per day is higher among those of whom the fathers with a university or higher degree $(53.8 \%)$; the ratio of the students brushing their teeth two times per day is higher between those of whom the fathers are primary school graduate $(62.2 \%)$, secondary school graduate $(78.6 \%)$ and high school graduate $(64.5 \%)$. 


\section{DISCUSSION}

It is reported that oral hygiene habits vary between the students educated based on different disciplines[12]. Therefore, we have grounded our study on students in different provinces and faculties. We tried to maintain the number of participants from both faculties equal in order to compare the statistical results. Based on volunteers at the faculties, we can state that male students participated less. This prevented to obtain a gender-based habit comparison.

In the study, the relations were analyzed between the education level of the family and the child's periodontal health, awareness, and knowledge of the caretakers on dental health and the child's periodontal health, as well as the education level of the family and dental health of the family, where no significant relationships were found[2]. As for preschool children, it is reported that forming a habit of toothbrushing is very challenging and that families should become more involved by having increased awareness [3,4].

In our study, we determined that students in both faculties received their tooth brushing education from their families. But it would be accurate to note that duration and intervals of brushing are established within time.

Although sugary foods and beverages in our daily lives are known to be a critical factor in tooth decay, no brushing habits have been established to provide oral hygiene within everyday activities. We believe that this is due to the fact that it might be difficult to provide daily care. Studies are reporting that it is vital to balance the daily sugar consumption because of such difficulty[8].

Although the effect of sugary foods and beverages on the teeth is general knowledge, students in both faculties do not have a habit of toothbrushing after consumption of sugary foods. The results of our study were similar to the results of the study, in which many participants reported that utilizing a firm toothbrush would be more successful in this respect[12]. The toothpaste manufacturers try to stand out with the features in sales. There are studies on such features. In addition, it is presumed that toothpaste is essential in ideal cleaning $[7,12]$.

In our study, we questioned whether participants select toothpaste based on such features and their thoughts about the importance of the amount of use. It can be stated that, whereas the amount of toothpaste is important for both groups, dentistry students use less in amount. We can link the foregoing to the education they have received, and to the fact that they are aware of the sufficient amounts for proper cleaning.

Brushing teeth, flossing, using mouthwash, and cleaning the tongue twice a day, along with eating healthily and regularly visiting a dentist, are the measures to reduce the risk of gingival diseases and caries. In addition, it is essential to clean the tongue from foods for sustainable oral hygiene. While dental floss should be a habit to be acquired at a young age, studies are showing that it varies according to both individual and social perception[6,10,13].

We assume that the reason for the higher utilization of dental floss between dentistry students is the education they have received. We found that tongue cleaning was not carried out in either group. We can attribute such fact to the lack of social awareness.

In a study conducted on 101 people aged eighteen, it was found that the front sides of teeth were brushed more than the backsides[5,9]. In our study, when we asked individuals to evaluate themselves in such respect, they reported that there was no difference between the surfaces of their teeth. However, we presume that clinical trial results might disprove such a statement. Accordingly, we believe that repeating the details of toothbrushing at every annual control is essential for long-term success.

In response to our first hypothesis, which states that there will be no difference between dentistry and biomedical departments in terms of primary dental care habits, $56.4 \%$ of the participants reported that they adopted their toothbrushing habits from their families, confirming our hypothesis. It indicates that families significantly affect oral hygiene habits.

On the other hand, our second hypothesis stated that dental care habits might change in detail with the education received in time. Results of the study revealed that the amount of paste used, the use of dental floss, brushing twice a day, one of which being before bedtime, are significantly higher in dentistry students. We interpret the foregoing as an indication that habits are used more effectively with the training received, confirming our second hypothesis.

\section{CONCLUSION}

Tooth brushing habits should start with the growth of teeth. Such habit is initially adopted from the family. Correct brushing is established upon the guidance of the dentist. Therefore, teaching proper toothbrushing techniques to the families should be aimed. This will enable socially healthier oral hygiene, thus creating high awareness communities.

\section{Clinical Relevance}

Scientific rationale for study: Oral hygiene is the first step for the healthy circulatory system. Personal nutrition habit, effective brushing time and technique, using correct instruments for cleaning teeth and tongue are the part of the obtain the good oral hygiene.

Principal findings: Oral hygiene should be take consideration by the parent from the beginning of the life. Teeth brushing should started till the eruption of the tooth. When the primary teeth erupted interface cleaning should started. So that patient knowledge is very important. Dentist are the key in that point to show the parents the right way. 
Practical implications: In our research we want to show the importance of the parents knowledge and also to show the education in dentistry will effect the dentist life way so that it will effect the social life whom they will treat in correct way.

\section{REFERENCES}

[1]. Alshehri FA. The use of mouthwash containing essential oils (LISTERINE $\square$ ) to improve oral health: A systematic review. Saudi Dent J. 2018 Jan;30(1):26.

[2]. Gülhan A, Sandallı N, Akıncı T, Uz M, Özkan S. Ailenin Çocuğunun Diş-Ağız Sağlığı Üzerindeki Etkilerinin Araştırılması. J. of Ist. Uni. Fac Dent. 1986;20:54-63

[3]. Boustedt K, Dahlgren J, Twetman S, Roswall Tooth brushing habits and prevalence of early childhood caries: A prospective cohort study. J.Eur Arch Paediatr Dent. 2020 Feb;21(1):155-159

[4]. Quek SJ, Sim YF, Lai B, Lim W, Hong CH The effect of parenting styles on enforcement of oral health behaviours in children. Eur Arch Paediatr Dent. 2020 May 16. doi: 10.1007/s40368-020-00537-7

[5]. Rajapakse PS, McCracken GI, Gwynnett E, Steen ND, Guentsch A, Heasman PA Does tooth brushing influence the development and progression of noninflammatory gingival recession? A systematic review. J Clin Periodontol. 2007 Dec;34(12):1046-61.

[6]. Cuculescu M, Slusanschi O, Boscaiu VR, et al. Selfreported oral health-related habits, attitudes and knowledge in adults from Portugal, Romania and Sweden-A comparative study. Int J Dent Hyg. 2019 Nov;17(4):359-368

[7]. Mohankumar K P, Priya N K, Madhushankari G S Anti cariogenic efficacy of herbal and conventional tooth pastes - a comparative in-vitro study. J Int Oral Health. 2013 Apr;5(2):8-13.

[8]. van Loveren C Sugar Restriction for Caries Prevention: Amount and Frequency. Which Is More Important? Caries Res. 2019;53(2):168-175. doi: 10.1159/000489571. Epub 2018 Aug 8.

[9]. Winterfeld T, Schlueter N, Harnacke D, et al. Toothbrushing and flossing behaviour in young adults- a video observation. Cin. Oral Investig 2015;19(4):851-8.

[10]. Melo P, Marques S, Silva OM. Portuguese selfreported oral-hygiene habits and oral status. Int. Dent. J.2017 Jun;67(3):139-147. doi: 10.1111/idj.12273.

[11]. van der Sluijs E, Slot DE, Hennequin-Hoenderdos NL, van der Weijden GA. Dry brushing: Does it improve plaque removal? A secondary analysis. Int $\mathrm{J}$ Dent Hyg. 2018 Nov;16(4):519-526.

[12]. Doğan B. Differences in Oral Health Behavior and Attitudes Between Dental and Nursing Students Clin. and Exper Health Science 2013:3;34-40.

[13]. Seerangaiyan K, Jüch F, Atefej F, Winkel EG. Taongue Cleaning Increases the Perceived Intensity of Salty Taste. J. Nutr Health Aging 2018;22(7):802-4. 